\title{
Guanine Nucleotide Exchange Factor
}

National Cancer Institute

\section{Source}

National Cancer Institute. Guanine Nucleotide Exchange Factor. NCI Thesaurus. Code C17494.

Proteins that catalyze the release and exchange of GDP for GTP from GT P-binding regulatory proteins, which are active in the GT P-bound form. 